https://helda.helsinki.fi

\title{
Context in Mechanism-based Explanation
}

\section{Pozzoni, Gianluca}

2021-02-03

Pozzoni , G \& Kaidesoja , T 2021 , ' Context in Mechanism-based Explanation ' , Philosophy of the Social Sciences , vol. 51 , no. 6 , pp. 523-554 . https://doi.org/10.1177/0048393121991657

http://hdl.handle.net/10138/339118

https://doi.org/10.1177/0048393121991657

cc_by_nc_nd

acceptedVersion

Downloaded from Helda, University of Helsinki institutional repository.

This is an electronic reprint of the original article.

This reprint may differ from the original in pagination and typographic detail.

Please cite the original version. 


\title{
Context in mechanism-based explanation
}

\section{Gianluca Pozzoni and Tuukka Kaidesoja}

Penultimate draft of the article that has been published in Philosophy of the Social Sciences in 2021.

\begin{abstract}
In this article we discuss the issue of context-dependence of mechanism-based explanation in the social sciences. The different ways in which the context-dependence and context-independence of mechanismbased explanation have been understood in the social sciences are often motivated by different and apparently incompatible understandings of what explanatory mechanisms are. Instead, we suggest that the different varieties of context-dependence are best seen as corresponding to different research goals. Rather than conflicting with one another, these goals are complementary to each other and therefore pave the way to a methodologically more cooperative approach to mechanism-based explanation in the social sciences.
\end{abstract}

\section{Introduction}

According to some influential accounts, to provide a scientific explanation of a given phenomenon - social or otherwise - is to answer a "why-question" about its occurrence (Braithwaite 1953, Hempel 1965, Bromberger 1966, van Fraassen 1980, Elster 1989). Within the social realm, typical explananda include both general facts and historical events. Instances of the former are statistical facts like the apparently higher rate of health issues that can be found in lower-income social groups with respect to higher-income social groups in an economically unequal society. On the other hand, historical explananda can include punctual events like Ronald Reagan's electoral success over Jimmy Carter in the 1980 U.S. elections as well as more large-scale processes such as the emergence of capitalism in Western civilization. Accordingly, scientific explanations of social phenomena of this kind can be seen as answers to why-questions of the form: "Why are health issues 
more frequent in low-income social groups?", "Why did Ronald Reagan win in the 1980 presidential elections?" or "Why did capitalism emerge in Europe?" 1

A salient feature of recent philosophy of science is the emphasis on mechanism-based explanation (MBE) as the most adequate way of answering such causal questions. Moving from a general dissatisfaction with the so-called "covering-law" model of explanation, an increasing number of philosophers of science have begun to characterize explanation in mechanism-based terms, both in the natural and in the social sciences (e.g. Harré 1970; Wimsatt 1976; Bhaskar 1978; Salmon 1984; Elster 1989; Bunge 1997; Hedström and Swedberg 1998). Beginning in the 1990s, the debate on mechanisms and their role in causal explanation has grown in the most diverse areas of scientific research, especially since the publication of Machamer, Darden and Craver's (2000) influential article on MBE in neurobiology and molecular biology. As a result, a wide variety of different and mutually incompatible accounts of mechanisms are available in the existing literature (e.g. Glennan and Illari 2018). Nonetheless, despite considerable cross-fertilization the debate on MBE in the social sciences and the new mechanistic philosophy of science have by and large developed in parallel, and can in principle be addressed independently of one another. Rather than delving into the intricacies related to the definition of causal mechanisms and their nature, we shall begin our discussion by considering the explanatory role they may play in answering the why-questions of the type described above.

Since MBE is typically regarded as a sub-species - or, in some cases, as the epitome - of causal explanation, it may be said that it provides because-answers to why-questions. At a minimum, MBEs answer questions regarding why an event happened - or why a certain state of affairs is the case - by citing a concatenation of earlier events and/or other causal factors as its causes. Thus, for instance, one may explain the high frequency of health issues among deprived social groups in terms of the absence of universal health care combined with reduced economic means - and, consequently, reduced access to health care and healthy working and housing environments - rather than, say, by citing the poor economic and lifestyle choices made by individuals. Similarly, one may explain Reagan's victory in the 1980 presidential elections by

\footnotetext{
${ }^{1}$ This approach is sometimes referred to as "the erotetic model of explanation" (Risjord 1998, Risjord 2000, Khalifa 2004). Other authors have insisted on the significance of explanation-seeking questions - especially contrastive questions of the form “Why P rather than Q?" - in guiding explanatory research (Garfinkel 1981). Even though not all authors subscribe to this approach, framing causal explanation in erotetic terms is a particularly instructive way of introducing the issues of causal explanation that are at the center of recent philosophy of (social) science.
} 
citing Jimmy Carter's failed attempt to resolve the Iran hostage crisis of 1979 (Elster 2007, 9), or the emergence of capitalism in the West in terms of the advent of Protestantism and the spirit of antitraditionalism and diligence with which it infused the economic behavior of the European population (Weber $2012[1904 / 1905])$.

However, many an author have argued that to provide because-answers is not enough for a causal explanation to qualify as mechanism-based. Functional explanations also provide answers to why-questions: confronted with the question, "why does institutional or behavioral pattern $x$ exists or persists in a given group?", functionalists offer some variant or another of the answer: because $x$ has the beneficial consequence $\varphi$ for said group. Whether functional explanation is a special case of causal explanation or rather an alternative to it is a matter of debate; however, it is beyond doubt that it can only be considered as mechanism-based insofar as it details rather than (tacitly) presuppose a causal mechanism (Elster 1983). Unlike non-mechanistic functional explanations, the argument goes, MBEs refer to a concatenation of earlier events and factors as the explanantia. In this sense, one might simply characterize MBE vis-à-vis other because-explanations by adding the requirement that the causes cited be temporally prior to the effects, and that an etiological account of causal production or propagation be thereby provided. However, MBEs are often considered as also distinct from true causal statements about singular causal processes. True causal statements of this sort do in fact offer etiological accounts of causation in terms of sequences of events, but unlike MBEs, and not too dissimilarly from functional explanations, they presuppose rather than detail the underlying mechanism. In Elster's $(2007,21)$ example, if we are told that a person died from eating rotten food, we can only assume that the mechanism was food poisoning, but the mechanism is not actually present in the purported explanation.

In explanations of events, the peculiarities of MBE also seem to concern the temporal and/or conceptual proximity between the event to be explained and the causes cited in the proposed explanation of such event. When facing a punctual historical question like the one concerning the causes of Reagan's victory in the 1980 election, one may answer by citing the true causal fact that Reagan won more electors from different states than Carter did. Patently, however, such a (correct) because-answer does not amount to a satisfactory causal explanation even though it could be considered a legitimate etiological account of the 
1980 electoral results. As a consequence, one may wish to add the requirement that explanatory mechanisms feature causal factors that are sufficiently removed from the outcome both at the temporal level (e.g. the 1979 Iran hostage crisis or the enduring economic crisis) and at the conceptual level (e.g. the declining popularity of Democrats and of liberal policies in general).

To clarify more thoroughly in what peculiar sense mechanisms answer why-questions as opposed to other etiological accounts, one may say that MBEs reconstruct how an effect or a particular historical outcome is produced by identifying only the causally relevant features of the process that generated it. As Ylikoski and Kuorikoski (2010) put it, MBEs assume that explanation-seeking questions do not simply ask why something is the case; they also ask how a cause brought about the effect. In other words, underlying every why-question is a set of how-questions that must be answered in order to satisfactorily explain a phenomenon (Ylikoski and Kuorikoski 2010, 216). To answer those how-questions is to provide a MBE.

The very idea that mechanisms clarify the way in which an empirically identified effect or outcome is brought about instead of simply reconstructing a causal process presupposes that the abstracted functioning of the mechanism can be separated, at least analytically, from the empirical conditions that activate the mechanism and enable its operations in a particular environment. This separation is often framed in terms of a fundamental distinction between mechanisms and the contexts in which they operate. Advocates of a mechanism-based approach to social explanation disagree about the extent to which the contexts must be included in explanations of social phenomena or, conversely but equivalently, about the extent to which the explanatory power of mechanism lies in their relative abstractness and context-independence.

On many accounts of MBE, the separability between "context" and "mechanism" is secured by the basic assumptions of the mechanism-based approach. Unlike causal processes or bare events, mechanisms are typically defined in general enough terms as to be identifiable in different causal scenarios. Accordingly, MBE deliberately aims at singling out sets of causal factors that recur in a more or less wide variety of different contexts. Here, we use the expression "causal factor" in a non-committal way, and assume that it is compatible with different definitions and ontological understandings. Nonetheless, the regularity with which a causal factor is found to occur as well as the general characteristics of the mechanism identified by a researcher depends on a stipulation about the importance of the causal factors that are deemed to make 
up the explanatory mechanism. In fact, the operation of some mechanisms may be found to be so tightly interconnected with the surrounding conditions that the corresponding MBE cannot be transposed to other contexts without losing most if not all its explanatory relevance (Glennan 2010; Little 2016).

In the face of such variability, one is tempted to select a comprehensive account of MBE and causal mechanisms as one deems appropriate to one's research goals or epistemic views, and rule all others out as inappropriate or misguided. The above characterization of MBE in terms of answers to causal how-questions is compatible with many different accounts of causation and, consequently, of different accounts of causal mechanisms that are assumed in answers to these questions in the social sciences. In this article, we wish to remain agnostic with respect to one definition of explanatory mechanisms or the other, and focus on different accounts of mechanisms with respect to their dependence on (or independence of) the context. We argue that philosophical debates that include different and incompatible assumptions about the context(in)dependence of causal mechanisms arise to a large extent from a tendency to ignore the variability of research goals and methodological approaches to which different views of MBEs are connected. In order to make this point, we first discuss different ways in which context-dependence and context-independence of explanatory mechanisms have been understood in the social sciences, including the ideas that have motivated these views. Then we make a distinction between two different concepts of mechanism presupposed in highly context-independent and highly context-dependent accounts of MBEs, respectively. Although some debates about MBEs in the social sciences still revolve around these two incompatible accounts of causal mechanisms, our objective is not to reinforce them.

Instead, we aim to bridge the gap between the contending parties by making a distinction between three different senses of context-dependence of mechanisms that correspond to different goals of social research: the construction of explanatory theories, the identification of causal pathways in different populations, and the explanation of single outcomes. We suggest that all of these three goals are legitimate and that they are best seen as complementary (rather than incompatible and mutually exclusive). Our conclusion is that this way of framing the question of context in MBE contributes a less conflictual and more integrated understanding of the mechanism-based approaches to social explanation, although we do not 
claim that this framing alone resolves the philosophical issues that arise in attempts to integrate different methodologies, for example, in multi-methods social research.

\section{Varieties of context-dependence}

Authors who adopt a relatively context-insensitive approach to the use of mechanisms for explanatory purposes typically assume that explanatory theories are better the broader their scope, and therefore assume that good theories must be applicable to explaining a broad range of different social phenomena. In the social sciences, this usually translates into building or empirically testing explanatory theories that make the least reference to particular actors, institutional settings, historical conjunctures, geographical areas, or other specification of the social context in which the phenomenon of interest has been found to occur. Theories of this sort are held to explain what economist Nicholas Kaldor (1957) has termed "stylized facts", which are often taken to be the quintessential explanandum of mechanistic theories (Hedström 2005; Hedström and Ylikoski 2010).

Reference to Kaldor's stylized facts from economics is no coincidence. Given the premium it puts on generality, and hence abstractness, of theories, a highly context-independent approach to the explanation of social phenomena is often built-in in economic modeling, particularly in neo-classical economic theory. In it, equilibrium models of "free markets" (or "perfectly competitive markets") are assumed to explain market prices in terms of the balancing of supply and demand irrespective of the concrete dynamics of exchange, size of business firms, actual interests of actors, their positioning in the bargaining, and so on. To be sure, it may be argued that the mechanisms behind the model of perfect competition are not as much contextindependent as they may appear, since suppliers and demanders are only assumed to converge on equilibrium in the specific context of competitive market economies. More recently, many economists have also begun to pay attention to the various ways in which actual markets may fail to conform to their ideal of the perfectly competitive markets (e.g Rodrik 2015, 67-72). To see in what sense this approach can still be seen as actually presupposing a high degree of context-independence, let us consider a more extreme but not entirely unrelated example. 
Gary Becker's (1976) famous "economic approach to human behavior" is based on the idea that the rational-choice mechanisms based on the assumptions of maximizing behavior, market equilibrium, and stable preferences can be extended to "all human behavior", including traditionally non-economic phenomena such as racial discrimination, the political behavior of democracies, criminal behavior and public policy responses to it, household decisions to attend school or take care of their own health, individual attitudes toward marriage and childbearing, altruism, and many others. In a similar vein, mechanisms that had been previously seen as characteristic of the exchange of market goods and services have been applied to explananda in contexts as diverse as church attendance (Azzi and Ehrenberg 1975) and the extinction of animals (Smith 1975). As Becker wrote in the very first introductory line of his collected work on the subject, the economic approach is used to understand "human behavior in a variety of contexts and situations" (Becker 1976, 3, emphasis added). Although Becker does not specifically defend MBE vis-à-vis other models of explanation, the fundamental assumptions of the economic approach - utility maximization and the determination of prices in relation to the opportunity costs of scarce resources - are often seen as fullyfledged economic mechanisms (e.g. Maurer 2016).The peculiarity of these mechanisms is that they are general enough as not to make reference to the specific goods and wants that are being allocated nor to the specific features of institutional settings where goods are exchanged, and therefore they can be identified in the most diverse contexts, from the market price of eggs, to the costs of child-rearing, to determining the high value of large herbivores hunted to extinction by archaic humans. In other words, Becker and his followers re-conceptualize all social phenomena in abstract terms as instances of market exchange between rational actors which, at least in principle, enables them to apply the economic approach to all social phenomena. $^{2}$

\footnotetext{
${ }^{2}$ The notion that the rational action of individuals can be considered a genuine social mechanism has been criticized by Ruonavaara (2012) on the basis of a distinction between social and cognitive mechanism, which allows for a further distinction between (social) mechanisms and theories of actors. The social-cognitive distinction builds on Hedström and Swedberg's (1998) definition of social mechanisms, which Ruonavaara characterizes as "regularly observed, causally effective patterns of interaction between actors" (Ruonavaara 2012, 6.2, emphasis added). However, it should be noted that Hedström and Swedberg (1998) also consider situational and action-formation mechanisms (including rational action) to be legitimate social mechanisms on a par with transformational mechanisms of interaction. More generally, as we argue in the first half of this paper, there is no general agreement on an unequivocal definition of social mechanisms.
} 
At the other end of the spectrum of context-sensitivity of MBE lie those explanatory theories that tend to provide large amounts of context information while detailing the presumed causes of the phenomenon under consideration. These explanations typically take the form of case-based narratives that seek to account for the occurrence of particular events by detailing how the sequence of events that led up to those events unfolded. Resort to narrative explanations is usually motivated by an emphasis on the contingency and "path dependence" (Pierson 2000) of social processes, which require for the investigator to identify the specific "critical junctures" (Collier and Collier 1991) that determine the course that events take in a given setting. One example of this type of explanation is organizational sociologist Charles Perrow's (2002) influential study on the rise of corporate capitalism in the nineteenth-century United States, despite the fact that the author does not explicitly adhere to the idea of MBE. By the 1910s, Perrow argues, large bureaucratic organizations had become dominant in all sectors of U.S. society, while only very few of them existed in the period between the Civil War and approximately the 1890s - all of which were concentrated in the heavy industry. A question to be asked in this respect would then be: how did it come about that the United States developed a distinctively corporate economic system at the turn of the nineteenth and the twentieth century?

For Perrow, the explanation of this development is to be found in distinctively organizational features that characterize the U.S. system. Unlike Europe, and indeed because of American colonists' fear of reproducing the European concentration of wealth and power, the United States witnessed the construction of a "weak" state instead of a strongly regulative state. Over time, the lack of state regulation allowed private organizations, such as early railroad companies, to grow almost without limit and shape the distinctively corporate form of U.S. capitalism. Ultimately, what Perrow calls "the key mechanism for the organizational concentration of wealth and power" (31, emphasis in the original) is the conjunction of the possibilities offered by the early nineteenth-century emergence of a new legal form of corporation that limited liability of shareholders, as well as by the emergence of a deregulatory state, together with the organizational interests of growing firms and their drive toward profit. However, Perrow insists, this mechanism materializes contextually into an entirely contingent, happenstance, and path-dependent process: 
Had not the founding fathers had such a taste of the costs of centralized power from England and Europe, they might not have established a federated political system that allowed private organizational wealth, when it appeared, such a free reign. ... Had the U.S. population of, say, 1850 been achieved in 1650, a European structure of production with guilds and trades and tenant farmers could have been in place and resisted the leveling of social institutions that industrialization, if unchecked, will produce.

... Had the Lowells and Cabots of Boston reinvested their wealth in an expanded merchant fleet instead of the power loom on remote rivers, we might have left mass-produced cheap textiles to the English to produce (and then to India; the Lowells had to get a special tariff to block Indian goods), and established a fine goods industry with small organizations, on the low-powered streams that dotted the New England coast. Had not the Irish potato famine occurred, wage dependency would not have overwhelmed the United States so quickly and easily, just when factories appeared. Had the Panic of 1837 not occurred, just as the railroads were getting underway, public investment could have been so paramount that effective governmental regulation of the railroads would have been demanded and perhaps achieved, even despite a weak federal state. (Perrow 2002, 235)

As Perrow's analysis illustrates, MBE in within-case analysis may be highly sensitive to the causal role of contextual factors that depend on the nature, capabilities, and actions of the actors involved, as well as on the configuration of institutional frameworks and organizational structures - and even environmental factors such as the specificities of the social site and natural surroundings in which the phenomenon under consideration occurs. The resulting explanation thus incorporates a great deal of detailed information about the context and can hardly be generalized or transposed to other explanatory contexts (for other examples of this type of MBEs, see also Glennan 2010 and Beach and Pedersen 2013, 18-21; 63-66).

In between the two extremes of highly context-insensitive and highly context-sensitive MBE lies a wide spectrum of approaches that account for social phenomena at differing degrees of generality. A paradigmatic example of a moderately context-independent (or context semi-independent) explanation is Robert K. Merton's (1968 [1948]) theory of "self-fulfilling prophecies" by which widespread false beliefs may result in actions that will make the originally false beliefs come true. Merton illustrated this theory by telling the story of the Last National Bank, the false rumor of whose upcoming bankruptcy caused flocks of 
customers to rush to the tellers' cages in order to withdraw their deposits while the bank was still solvent. Inevitably, the massive demand of cash caused the previously stable bank to actually become insolvent and made the initially false rumor come true. Merton defined this fictional episode as a "familiar type-case", whose underlying logic is common to "many, if indeed not most, social processes" (Merton 1968 [1948], 475476). Not only bank runs, but also students' failures in examinations due to test anxiety as well as ethnic conflicts engendered by racial prejudices exhibit for Merton the logic of self-fulfilling prophecies.

Michael Biggs (2009) identified the self-fulfilling prophecy in a wide range of paradigmatic examples that include investment bubbles, the Placebo effect, reactive conflicts, and the performative effects of interpersonal expectancies and social conceptions. Nonetheless, Biggs cautiously notes that the self-fulfilling prophecy demarcates a particular type of dynamic process rather than encompassing all of social life. For one thing, the self-fulfilling prophecy must be a causal sequence that links a belief to a behavior and the behavior to the fulfillment of the prophecy. In other words, the (false) description of a situation must evoke a behavior which in turn must change the situation in such a way that the initially false conception becomes true. This distinguishes the self-fulfilling prophecy from mere confirmation bias or post-hoc rationalizations, in which beliefs have no effect on how the situation changes over time. Moreover, the self-fulfilling prophecy is based on a misapprehension of the misbelief-behavior-outcome causal sequence on the part of the actors, who neglect that their actions may have an effect on how the situation conforms to their (false) beliefs. This distinguishes the self-fulfilling prophecy from self-enforcing conventions (such as the driving side in a given country), in which everybody comprehends that the convention is enforced by their own acting in accordance with it.

Because it embodies a causal sequence, the self-fulfilling prophecy has been characterized as a causal mechanism. However, the causal sequence of the self-fulfilling prophecy is specific enough to be applicable solely to dynamic processes that are generated by a misapprehension of the causal connection that links a prophecy to its fulfillment via prophecy-governed behavior. The mechanism scheme of the self-fulfilling prophecy can be used to explain only the class of phenomena that present a similar causal structure. For this reason, Hedström and Bearman (2009) characterize the self-fulfilling prophecy as a "semigeneral mechanism". This mechanism scheme, they argue, "has limited scope in that it only is relevant for explaining 
certain types of phenomena, but it is general in the sense that it makes no reference to time, place, identity of actors, content of beliefs, or type of actions" (Hedström and Bearman 2009, 7).

\section{Mechanisms and context}

Hedström and Bearman's advocacy of semigeneral mechanisms in the social science is based on a revitalization of Merton's own idea of "theories of the middle range" - i.e. "theories that lie between the minor but necessary working hypotheses that evolve in abundance during day-to-day research and the allinclusive systematic efforts to develop a unified theory that will explain all the observed uniformities of social behavior, social organization and social change" (Merton 1968 [1949], 39). As Hedström and Udehn (2009) note, Merton does not explicitly discuss MBE as the most adequate model of social explanation, let alone with specific reference to theories of the middle-range. Nonetheless, elsewhere in his major theoretical work he defines the social mechanisms that articulate "role-sets" as "the social processes having designated consequences for designated parts of the social structure", and the middle-range theory of role-set as concerned "with the analytical problem of identifying the social mechanisms which produce a greater degree of order or less conflict than would obtain if these mechanisms were not called into play" (Merton 1968 [1949], 43-45).

More generally, Merton's view of sociological theory as well as his empirical work have been highly influential on a large part of contemporary mechanism-based social science, for which middle-range theorizing translates into semigeneral MBE (Pawson 2000; George and Bennett 2005; Hedström 2005; Hedström and Bearman 2009; Hedström and Udehn 2009; Hedström and Ylikoski 2010). On the other hand, Merton's defense of middle-range theorizing mainly served a critical purpose, i.e. as a warning to steer sociology between the Scylla of empirically vacuous "grand theory" and the Charybdis of "sheer description" of the social phenomena that require explanation. Accordingly, his characterization of middle-range theory is rather vague and the merits of middle-range theorizing per se remain unelaborated on (Kaidesoja 2019).

Merton makes it clear that the role of sociological theory is to direct the inquirer to hypotheses that can be empirically tested. He also makes clear, however, that theories of the middle range are compatible 
with the "total systems" of sociological theory. His skepticism towards the latter derives primarily from practical and contingent limitations rather than from general considerations about the viability and desirability of such totalizing systems. Merton (1968 [1949], 43) notes for instance that the total systems of sociological theory of his time are "sufficiently loose-knit, internally diversified, and mutually overlapping that a given theory of the middle-range [...] can often be subsumed under comprehensive theories which are themselves discrepant in certain respects". Hence, in Merton's (1968 [1949], 45) view, confidence in the possibility of formulating a general sociological theory here and now is "a premature and apocalyptic belief. We are not ready. Not enough preparatory work has been done". It is primarily for this reason that sociological theorizing requires middle-range abstractions, i.e. abstractions that are "close enough to observed data to be incorporated in propositions that permit empirical testing".

Even more generally, Merton's polemic against the untestable systems of received sociological theory - primarily Talcott Parson's structural-functionalism - led him to characterize this pole of the range of sociological theorizing more carefully than its opposite, namely, that of "sheer descriptions" and "minimal working hypotheses". As a consequence, little is said about why the semigeneral mechanisms of middlerange theories need to make abstraction from contextual descriptions. In part, this descends from his conforming to the orthodoxy of his time, namely, that theories consist of axiomatic systems of laws (or approximations to them) from which to derive empirically testable hypotheses (Hedström and Udehn 2009). Modern mechanism thinking in the social sciences, however, has risen to a great extent from skepticism about the explanatory power of laws (Hedström and Swedberg 1998; Elster 1999; Mahoney 2001; Hedström 2005; Hedström and Bearman 2009; Little 2009). Insofar as they provide constitutive explanations of how a concatenation of causes brings about an effect, mechanisms are said to open up the black box of law-like correlations between dependent and independent variables and show the cogs and wheels of internal causal production.

This is where context enters the equation again. The inherent generality of covering laws also implies that the law-like association between a cause and its effect is exceptionless with regard to the contextual causes that may contribute to the production of that effect or preempt it. MBEs, by contrast, make no claim to such exceptionless generality. In fact, they typically state the conditions under which the chain of causal 
production is carried through (Elster 1989, 8-9). However, despite this fact and with some important exceptions (e.g. Pawson 2000; Elster 2007; Falleti and Lynch 2009; Sayer 2010; Little 2009; 2011; 2016; Ruonavaara 2012), the notion that the effects of mechanisms are dependent on the context in which the mechanisms are activated has received little philosophical or methodological attention. In one of the few systematic treatments of the role of context in MBE in the social sciences, Falleti and Lynch $(2009,1152)$ define the context of occurrence of mechanisms in deliberately broad terms as "the relevant aspects of a setting (analytical, temporal, spatial, or institutional) in which a set of initial conditions leads (probabilistically) to an outcome of a defined scope and meaning via a specified causal mechanism or set of causal mechanisms". This definition is based on Mario Bunge's (1997) notion that mechanisms materialize within "concrete systems" that determine their functioning and are in turn driven by mechanisms in the transformation of their composition, as well as on Ray Pawson's $(2000,296)$ idea that "the relationship between generative mechanisms and their effects is not fixed but is contingent upon context".

The gist of Bunge's, Pawson's, and Falleti and Lynch's understanding of context is that the activation of mechanisms, and therefore the occurrence of a certain outcome, is determined by a set of relevant conditions in the surroundings. Although mechanisms may have a tendency to regularly bring about a certain outcome, they are not deterministic: "the same mechanism operating in different contexts may lead to different outcomes" (Falleti and Lynch 2009, 1151). This idea is also consistent with Jon Elster's $(2011,26)$ claim that mechanisms "are triggered under generally unknown conditions or with indeterminate consequences", as well as with Daniel Little's $(2009,2016)$ recent remarks about the "heterogeneity" of the social world - a consequence of which is that mechanisms bring about specific effects as a result of a variety of causes coming together in "highly contingent conjunctions" (Little 2016, 6).

In general, most proponents of MBE, at least in the social sciences, seem to agree that the causal action of a mechanism is at least partly determined by context. Arguably, the reason for this lies in the aforementioned interpretation of MBE in terms of answers to how-questions. As Elster (1989) argued, this idea allows one to distinguish mechanisms from assertions about necessitation: to say that MBEs show how an event happened or an outcome was produced does not exclude that the mechanism might be preempted by another. This makes it irrelevant that the same event or outcome might have been brought about in a 
different way; what matters instead is relatively fine-grained knowledge about what actually happened. This is also one way of arguing that behind every why-question about what actually happened lurks a howquestion that begs for the relevant mechanism to be uncovered.

Such understanding of the context-relativity of the effects of mechanisms may certainly rule out opposing but equally extreme positions about the complete context-independence of mechanisms or, conversely, about the indistinguishability - even at an analytical level - between mechanisms and the buzzing variety of contextual conditions that may or may not activate it. Yet the idea that the effects of mechanisms are indeterminate in the absence of context still allows for different degrees of what Falleti and Lynch (2009) call the "portability" of mechanisms across different contexts:

Of course, defining a mechanism as a portable concept that describes how causation occurs does not mean that it will operate in every context. Some mechanisms seem quite general and are even presumed by some to operate universally-rationality, for example, in the sense of individuals acting to maximize their perceived utility. But many other mechanisms are not nearly so ubiquitous. Some mechanisms apply only to a subset of all possible contexts. Boundary control is one such example; another is the circular flow of power that is hypothesized to operate in Leninist regimes ... (Falleti and Lynch 2009, 1148)

The heart of the matter, then, seems to lie in an ambivalence between the context-dependent nature of mechanistic causation and the aspiration towards "portable" mechanism-based explanatory theories that have broad scope and general applicability.

\section{Two concepts of mechanisms...}

General applicability and breadth of scope are indeed two of the most widely celebrated goals of scientific research (Whewell 2014 [1840-1847]; Friedman 1974; Kitcher 1981; Aronson 1984; Kiser and Hechter 1991; Morrison 2000, Mäki 2001), primarily because they bear promises of unification of what would otherwise be unrelated pieces of knowledge and thereby of increasing our understanding of the world. But causal depth and empirical adequacy are also highly praised criteria when assessing explanatory theories, especially as far as MBE is concerned. That MBEs purport to "open up the black box and show the nuts and bolts, the cogs 
and wheels of the internal machinery" (Elster 1983,24) suggests that alternatives to MBE may provide limited representations of actual causal processes, and that mechanisms are able to remedy such limitations. This argument in favor of MBE implies a commitment to the realist principle that explanatory theories should be formulated in terms of the processes that are believed to have actually generated the phenomena being studied (Harré 1970; Bhaskar 1978; Bunge 1997; Mahoney 2001; Hedström 2005, 28; Manicas 2006; Little 2016).

Since the two goals of generality and realism inherently trade off in the social sciences, there seems to be an irreducible tension between purportedly context-independent (or semi-independent) MBE and the context-dependent activation and operation of causal mechanisms. Most accounts of MBE seem to be aware of this tradeoff and explicitly situate themselves at different equilibrium points of what is believed to be an acceptable compromise between the realism and the generality of explanation. The question then arises, whether this tension can be reduced by modifying either of the two assumptions about the contextdependence of mechanisms and the context-independence of explanation. Falleti and Lynch already seem to go in this direction when they say that at least some mechanisms - e.g. the rational action of utilitymaximizing actors - are presumed to operate ubiquitously and universally. This derogates from the assumption that mechanisms are activated under contextual conditions that also determine their outcome.

Similarly, Jon Elster's $(1999,1)$ definition of mechanisms as "frequently occurring and easily recognizable causal patterns" seems to suggest that mechanisms are stable across contexts and are not dramatically affected in their structure by different contextual factors. More explicitly, Peter Hedström (2005, 42) has argued that mechanism-based theories of social action should aspire not to faithfulness to "token" individuals and social actions but to "'type' faithfulness, that is, abstract but realistic ideal-types of the logic of action". This prescription rests on the assumption that ideal-"types" of social action are real enough for the theories that describe them to be empirically accurate. In a different passage, Hedström is more explicit about the reality of such types; while accounting for the fact that interactions among individuals bring about different outcomes depending on how they are (contextually) arranged, he specifies that "different types of structural configurations of actors can be said to constitute different social mechanisms" (Hedström 2005, 26, emphasis added). Hedström and Bearman $(2009,7)$ make a similar point when they write that a 
mechanism is identified by "the specific pattern linking the types of entities to one another". What is at stake here is the contention that one may identify real patterns of causation that make other contextual factors less relevant for the sake of causally explaining the outcomes of such patterns. And while it is clear that these patterns do not amount to exceptionless laws that govern social phenomena, they nonetheless must present some degree of regularity in order to support generally applicable explanatory theories.

This downplaying of contextual factors is utterly rejected by other accounts of MBE. Speaking of cognitive mechanisms, for instance, William Bechtel $(2009,559-560)$ writes:

From a mechanist perspective, there is no basis for assuming that one could provide a complete account of the functioning of the mechanism in terms of the parts alone. The behavior of the mechanism depends not just on the parts but how they are organized and the context in which they are situated.

And with respect to biological mechanisms, he adds that "even the behavior of the parts themselves is often affected by the organization and environment in which they function and learning about such behavior requires studying the part in such a context" (Bechtel 2009, 560). Similar considerations apply a fortiori to the social realm, where phenomena present themselves with a distinctively higher degree of variability than they do in the systems studied by the life sciences. ${ }^{3}$ Daniel Little's recent discussion of the "heterogeneity" of the social world, for instance, has led him to characterize the latter as "an ensemble, a dynamic mixture, and an ongoing interaction of forces, agents, structures, and mentalities" (Little 2016, 7). Emerging from this heterogeneous and dynamic mixture that characterizes the constituents of the social world at the "molecular" level, social outcomes reproduce heterogeneity at the "molar" level. Accordingly, Little suggests that social scientists simply accept the fact of molar heterogeneity when confronting their research topics and attempting to explain social outcomes. Instead of looking for "sociological laws" or searching for answers to general questions like "why do revolutions occur?", the principle of social heterogeneity should lead social

\footnotetext{
${ }^{3}$ Although the nature of the distinction between "natural" and "social" phenomena may reasonably be questioned in many important respects, the regularity with which phenomena occur is a more well-established topic in the natural sciences than it is in the social sciences. The different characteristics of what are usually referred to as "natural kinds" vis-à-vis "human kinds" are evidence of this.
} 
scientists to "look ... for some of the different processes and mechanisms in play in a given item of interest, and then build up a theory of the whole as a concatenation of the particulars of the parts" (Little 2016, 7).

Along similar lines, Stuart Glennan (2010) has argued that the singular causal sequences that characterize historical events may not exhibit the stable properties of systems, and therefore cannot be accounted for by generalized MBEs that presuppose regularity in the interaction among the component entities of the mechanism. Singular historical events are usually explained by resorting to historical narratives. Yet, Glennan argues, narrative explanations can be legitimately called "mechanism-based" insofar as they are able to single out the activities and interactions of entities that are causally relevant to the outcome. Moreover, like the more context-independent variants of MBE, narrative explanations describe mechanisms which are activated by contextual factors that are exogenous and unpredictable, and which are short-lived and unstable. The only difference between systemic and historical MBEs lies in the fact that the mechanisms that feature in narrative explanations are, in Glennan's term, "ephemeral": the circumstances that bring together the various entities whose interactions are specific to the individual occurrence of each event, and therefore unrepeatable across contexts. Explanation of historical phenomena must thus be construed as descriptions of "ephemeral mechanisms".

What we have here are two distinct conceptions of social mechanisms on which different understandings of MBE in relation to context depend. On the one hand, mechanisms are conceived of as exhibiting a regular and stable causal structure in spatial and temporal terms. Social outcomes are produced by recurrent patterns of causal interaction among the components of the mechanisms. These can be adequately captured by explanations that are general in the sense that they are relatively independent of reference to contextual factors. The degree of regularity with which those mechanisms are deemed to operate in different contexts will determine the degree of generality and context-independence of the corresponding explanatory theory. (Mechanisms of rational action that are ascribed to utility-maximizing agents are assumed to operate almost ubiquitously, and therefore can be described by quasi-universal theories. Semigeneral mechanisms like the self-fulfilling prophecy studied by Merton are present only in a circumscribed range of processes and purport to identify important but delimited aspects of the phenomena to be explained, and therefore give rise to middle-range theories. And so on.) 
On the other hand, others see mechanisms as inherently dependent on the particular context in which they operate. That is to say, the very causal structure of the mechanism under consideration is affected or even determined by contextual causal factors that influence the way in which the components of the mechanism are organized and interact with one another to bring about the outcome of interest. Accordingly, MBEs describe the way those outcomes are produced by taking into account all the causally relevant activities and interactions of entities that contribute to generating the outcome - contextual or otherwise - and detail how they concatenate into a single causally generative process.

\section{4. ...or three concepts of context-dependence?}

In the 1990s, a debate took place in The American Journal of Sociology on the role of mechanism models especially rational-choice theory - in explaining concrete historical phenomena (see Gould 2004). In it, some authors defended the explanatory power of "general theories" (Kiser and Hechter 1991; 1998), while others defended the historically grounded articulation of explanatory theories (Quadagno and Knapp 1992; Skocpol 1994, 301-343; Somers 1998). The two concepts of MBEs described in the preceding section apparently reproduce this tension. However, as Somers (1998) has noted, the AJS debate was marred from the outset by an ambiguous understanding of what participants in the debate meant by "history" and "theory," respectively. In fact, the inconclusive outcome of the debate can be largely attributed to the essentially contested definition of mechanisms - or "theories" - vis-à-vis historical context (see also Manicas 2006, Appendix C). Luckily, the question of context in MBE needs not develop into such essential and unresolvable antinomies. In the remainder of this paper, we wish to propose a different way of looking at the problem. Specifically, we suggest that at least three different concepts of "context-dependence" (or "contextindependence") are at stake in the context-mechanism debate, irrespective of which concept of mechanism is being adopted by each author. As we will try to show in the final part of this paper, focusing on contextdependence in relation to different research goals may help avoid inconclusively debating different and mutually incompatible accounts of mechanisms.

\subsection{Theory-oriented context-dependence}


The first concept is mainly presupposed by advocates of what we have broadly characterized as "contextindependent MBE". A good starting point to clarify this concept is to recall Falleti and Lynch's definition of mechanisms as "portable concepts". Although this definition is primarily intended with an emphasis on the first term, namely the portability of mechanisms, to call mechanisms "concepts" is to presuppose a distinctive research strategy or "style of doing social science". Gudmund Hernes $(1998,78)$ describes this understanding of mechanisms as follows:

A mechanism is an intellectual construct that is part of a phantom world which may mimic real life with abstract actors that impersonate humans and cast them in conceptual conditions that emulate actual circumstances. A mechanism like a model is a stripped-down picture of reality; it is an abstract representation that gives the logic of a process that could have produced the initial observation. At the same time, this imaged world may seem vividly real; indeed, it is a conceptual copy that enables us to understand the real world.

In this view, theoretically postulated mechanisms do not describe any actual causal process but rather identify abstract possibilities. As Hernes indicates, mechanisms in this sense are how-possibly models that make no reference to actual actors nor to the actual social and historical contexts where their actions and interactions take place. When applied in explanations of actually occurring social phenomena, this type of theoretical mechanisms may become how-actually explanations on the conditions that there are empirically established social phenomena that are relevant to them and that their assumptions can be supported by empirical evidence.

Mechanisms thus conceived are theoretical objects - "concepts" or "ideal types" - i.e. parts of a theory. ${ }^{4}$ Accordingly, MBE instantiates what Beach and Pedersen $(2013 ; 2016)$ have called a "theory-centric" approach to social explanation: here, the primary goal of research is not so much to explain a single outcome as it is to build a relatively parsimonious theory that can help orient further research, or alternatively, to test an already existing theory. To this end, MBE must abstract from all elements that are considered irrelevant

\footnotetext{
${ }^{4}$ Other common phrases like "mechanism schemes" (Hedström and Bearman 2009) as well as characterizations of mechanisms in terms of "bits of theories", "pieces of scientific reasoning" (Stinchcombe 1993), or "analytical constructs" (Hedström and Swedberg 1998) are also indications of this.
} 
to the scope of the theory and which may be labeled the "context" in which the mechanism is posited to operate. When testing a theory or causal hypothesis, the researcher seeks to evaluate whether statistical or case-based evidence confirms the theory, i.e. whether the mechanism is present and functions as theorized or whether it fits with the data better than competing mechanisms. For this reason, the researcher must turn empirical evidence into a test for the presence or absence of the mechanism as it has been conceptualized in existing theorizing, i.e. by disregarding all causal factors that may be present in the setting but absent from the theory as it stands. Similarly, when inferring from a fact or event to an explanatory theory, the researcher must draw causal links between the temporal stages of the hypothesized mechanisms on the basis of selected pieces of evidence and disregard other pieces of evidence.

The criteria that are used to separate the relevant elements to be featured in the model from the irrelevant ones to be discarded depend on the aim and purpose of the model. Inquirers construct partial representations by isolating a few causally relevant factors for the purpose of assessing what effects they have under the idealized conditions of the model. The salience of these causal factors may be determined by a priori stipulations about the scope of the theory as well as by empirical work conducted to test the applicability of models in chosen settings. To bring the discussion back to mechanisms and context, what is considered as a bona fide component of the mechanism and what counts instead as a purely contextual cause will depend on theoretical as well as empirical criteria, such as the scope of the theory to be tested, the robustness of causal connections that are inferred from data gathered in different contexts, or the way concepts are operationalized in empirical research.

What is important to note here is that a theory-oriented concept of context-(in)dependence must not result necessarily in context-independent explanations. Although the inherent generality of some mechanism models may make them tailor-made for constructing context-independent explanations, other models allow for considerably lesser degrees of abstraction from context. Bengtsson and Hertting (2014), for instance, showed how "ideal-type" mechanisms of thin rationality can be successfully applied to case-study research, e.g. the study of participation in housing management among Swedish residents or the study of public-private cooperation in Swedish urban renewal. With reference to agent-based models, Gilbert (2008) and Squazzoni (2012) distinguish between "abstract", "middle range" and "facsimile" or "case-based" 
models. An example of how case-based or facsimile models may prove useful in constructing contextdependent explanatory theories is Dean et al.'s (2000) classic application of agent-based modeling to the study of the Kayenta Anasazi populations that occupied the prehistoric Long House Valley in the Black Mesa area of northeastern Arizona between 1800 B.C. and 1300 A.D. The model generates settlement locations by simulating Anasazi household agents' response to potential maize crop yields in different locations of the valley. In this way, Dean et al. are able to produce a possible reconstruction and hence an explanation of the history of Anasazi up to their disappearance from the Long House Valley. Their model predicts that environmental deterioration would make Anasazi survival in the valley unsustainable by 1300 A.D., which roughly fits available archeological data. The approximate match between the model and the data provides a test for the credibility of the model as a single-case explanation. As Boero and Squazzoni $(2005,4.20)$ put it, "this case-based model is a good example of empirical data-based ABM. The empirical target has timespace circumscribed dimensions. The goal is to understand a particular history. The mean is a realistic model able to mimic historical evolution". ${ }^{5}$

\subsection{Population-based context-dependence}

The distinction between the first and the second concept of context-dependence is rooted in the distinction between actor-based and variable-based approaches to theorizing in the social sciences. While most theoretical modelling approaches in the social sciences are actor-based, in the sense that theoretical models represent abstract actors with specific properties whose organized interactions produce a specific outcome, many sociologists have argued that those social researchers who have specialized in statistical methods often engage in variable-based theorizing that is in tension with actor-based theorizing (e.g. Hedström and Swedberg 1998, 15-17; Sørensen 1998; Goldthorpe 2001; Hedström 2005). Peter Hedström $(2005,105)$ goes so far as stating that, in the traditional variable-based approach to causal modeling, "theoretical statements have become synonymous with hypotheses about relationships between variables, and variables have replaced actors as the active subjects with causal powers". In other words, causal models of this kind are at

\footnotetext{
${ }^{5}$ For a different interpretation see Grüne-Yanoff (2009) and Grüne-Yanoff and Weirich (2010). The authors argue that the mismatch between the model and the data at the end of the period studied suggests that the model misses some crucial explanatory factors. Consequently, it cannot be considered a "full explanation" of the particular event under consideration - the Anasazi departure from the Long House Valley - but only a possible explanation that stands in need of an actual explanation.
} 
risk of losing sight of the social actors whose interactions are assumed to generate the statistical dependencies between variables. Nevertheless, the virtue of statistical models is that they enable one to generalize the model to the basic population if the model fits with the data (either by using population data or randomized sampling and estimation techniques). This feature of statistical models is not only important for descriptive purposes; it may also be utilized for explanatory purposes insofar as their assumptions are supported by empirical knowledge.

Unlike the theory-oriented approach, the population-based approach does not aim at building mechanism models for theory-guided research. Instead, causal mechanisms are invoked to aid causal inferences - which are typically understood in terms of counterfactual dependencies between the values of variables (e.g. Morgan and Winship 2007; Gerring 2010). This approach is particularly suited for research practices in which observational methods are used to produce data that represents population-level distributions of the values of variables. In these research practices, causal mechanisms are in the simplest case considered as intervening variables that mediate the observed dependencies between the values of independent and dependent variables, and thereby provide a causal pathway through which these variables may be causally related (e.g. Morgan and Winship 2007, 240-242). For example, one might hypothesize that the observed correlation between the low socioeconomic status and the increased probability of health issues in an economically unequal population is partly mediated by the intervening variables that represent the quality of working conditions, the quality of housing environments and the level of low-income related stress. $^{6}$

In this second sense, therefore, context-dependence is understood as the presence of a contextspecific mechanism that mediates between two causally related variables. Both the theory-oriented and the population-based approach conceive of explanation in terms of drawing connections in the abstract between the actors in the theoretical model and between variables in the statistical model, respectively. Operationally, however, the main difference between the two approaches is that the mechanisms tested or

\footnotetext{
${ }^{6}$ Although the notion that causal mechanisms are intervening variables has been questioned by the advocates of other accounts of causal mechanisms (e.g. Hedström and Swedberg 1998; Goldthorpe 2001; Hedström 2005; McAdam, Tarrow and Tilly 2001), this idea continues to play an important role in quantitative social research which relies on population-level data acquired by using experimental and observational research designs.
} 
identified in variance-based research cannot usually be generalized to other populations which have different composition from the one in which the causal hypothesis about intervening variables or causal pathways were formulated (e.g. Morgan and Winship 2007, 224). (Note that these "other populations" typically include the original population at a later point in time since the composition of populations changes over time.) Social researchers often motivate their ideas about relevant intervening variables and more complex path models by deriving them from the theories about the social or cognitive processes which may have generated the observed dependencies between variables. However, statistical models that include intervening variables, or more complex causal structures specifying the counterfactual dependencies between many variables, do not typically license causal inferences with respect to any particular individual in the population (nor her actions) unless it can be assumed that the population is causally homogenous in the relevant respects. Insofar as this condition is not met, as is often the case in social research, then causal models of this kind account only for average effects at the populational level.

Recent literature on causal modeling by means of causal graphs requires that causal dependencies between variables represented in the equations of the model should be invariant under some interventions and modular (see Woodward 2003; Knight and Winship 2013). Although some social phenomena may meet these conditions, it is debatable whether (or to what extent) this approach is suitable for causal analysis of the social processes that include complex social interactions (which are different from statistical interactions of variables). This is not to deny, however, that it may be possible to generalize a confirmed or estimated structural equation model to other populations with a similar composition in the relevant respects. To be sure, this requires new population-level data. However, comparative data about different populations may show that a mechanism is present in more than one context (and hence it is not peculiar to a single population) or that it does not affect the posited causal dependency between the two variables. Put differently, the question of the context-dependence of explanation in population-based approaches is an entirely empirical matter that cannot be settled a priori but is instead determined by evidence.

As we noted above, the population-based approach typically assumes a counterfactual account of causation, and usually regards causal mechanisms as intervening variables that represent causal paths between variables in causal models. Many advocates of explanatory mechanisms consider the intervening- 
variable account as non-mechanistic (e.g. Elster 1989; Hedström 2005; Hedström and Ylikoski 2010); therefore, one may take the population-based concept of context-dependence to be altogether alien to MBE. Nonetheless, more than one author consider explanatory mechanisms to be nothing but a series of intervening variables (e.g. King, Keohane, and Verba 1994; Opp 2005), while others have explicitly linked MBE to a counterfactual theory of causation (e.g. Morgan and Winship 2007). Most importantly, the populationbased approach need not be necessarily connected to an intervening-variable account of causal mechanisms nor to a counterfactual theory of causation. John Goldthorpe (2001; 2007), for instance, rejects both the counterfactual and the manipulationist view while defending a population-based approach in combination with actor-oriented theorizing. Instead of assuming the intervening-variable view of causal mechanisms, Goldthorpe $(2001 ; 2007)$ relies on a generative (or "mechanistic") account of causation and argues that a general action theory is needed to develop hypotheses about generative processes - or causal mechanisms - that could have produced the social phenomena that are established by using statistical methods. Hence, he suggests that after researchers have specified a theoretical model of the causal mechanism, they should use all kinds of evidence (including cross-population evidence) to test the implications of the theoretical model.

A distinction between "mechanistic evidence" from within-case analysis and "difference-making evidence" from population-level experimental or observational analysis (Russo and Williamson 2007, Illari 2011, Beach and Pedersen 2016) is also relevant here. The difference between these two types of evidence reflects one main difference between theory-oriented and population-based approaches to contextdependence. In the former, generalization typically proceeds from a single case to the theory (hence the name) by extracting a theoretical mechanism or model of mechanisms from the context in which it has been studied. The presence or absence of a mechanism in a given or novel context can thus be tested using "mechanistic evidence". The latter approach aims instead at establishing the difference that a cause makes to the (probability of) occurrence of its effect by using randomized controlled experiments and/or observational statistical analysis regarding a specific population, thereby producing "difference-making evidence".

\subsection{Case-oriented context-dependence}


The third concept of context-dependence (or context-independence) is based on what Beach and Pedersen $(2013 ; 2016)$ call a "case-centric" approach to social research. Case-centric strategies of research are adopted for the purpose of explaining individual outcomes that are deemed puzzling or of particular interest to social scientists (or even non-specialists). Such case-centric and outcome-oriented research design mandates that the explanatory theory not be parsimonious and instead formulate full-fledged MBEs that are developed by collecting and analyzing different types of data about the hypothesized causal process with specific emphasis on longitudinal qualitative data. In other words, comprehensive explanations are to be aimed for. Note that on this approach there is a correspondence between mechanisms - understood as the causal structures of real-world causal processes - and the way they are represented in the explanatory theory. Causal mechanisms are organized collections of entities and activities whose interactions conglomerate into sequences of events that produce the particular outcome of interest. Correspondingly, MBEs are considered accurate descriptions of how particular outcomes are produced by a causal mechanism (or by a conglomerate of causal mechanisms).

It is for this reason that MBEs often take the form of narrative explanations. But while those narratives can be understood as descriptions of mechanisms, these need not be "ephemeral" in Glennan's (2010) sense. In fact, whether mechanisms are ephemeral or repeatable is an entirely empirical matter that cannot be settled a priori. Analogously, while the generalizability of narratives is usually highly restricted if not downright impossible, some of their parts may describe mechanisms that are in fact present in different contexts. The exhaustive reconstruction of the causal pathway that led up to an outcome in a given context typically involves the reconstruction of "long causal chains" (Gerring 2012, 216) that can be broken down into shorter chains. As McAdam, Tarrow, and Tilly (2001) put it, mechanisms seldom operate on their own; they typically concatenate with other mechanisms into processes - which in turn are described by case-based narratives. However, mechanisms and processes form a continuum, and it is arbitrary whether one calls a delimited set of generative causes a mechanism, a family of mechanisms, or a process (McAdam, Tarrow, and Tilly 2001, 27).

McAdam, Tarrow and Tilly conventionally call "mechanisms" the parts of processes that are found to recur across different context. For instance, while investigating the causes of the U.S. civil rights movement 
they identify such mechanisms as "attribution of threat and opportunity", "social appropriation", or "innovation of collective action" that are at the basis of the 1955 bus boycott in Montgomery, Alabama itself one of the major sparks that set off the civil rights struggle of the 1960s. However, the same mechanisms are also present in other episodes of contentious politics that are as distant in time and space as the Parisian uprising of 1789 and the protest cycle in Italy between the end of the 1960s and 1970s. Although this procedure makes sense, it is debatable whether McAdam, Tarrow and Tilly succeed in specifying those mechanisms in an adequate way. It has been argued, for example, that many of their descriptions of mechanisms are mechanism sketches rather than mechanism schemas proper since they do not detail those component entities and their activities in a way that allows one to identify them in different cases such that the temporal stages of the proposed mechanisms remain robust (Norkus 2005, 386-369).

All the same, McAdam, Tarrow and Tilly's reconstruction of these episodes is distinctively narrative in character. In criticizing classic social movement scholarship for constructing static and single-actor models of contentious politics, they emphasize the dynamic causal complexity that characterizes each episode by producing different aggregate outcomes. Consider how McAdam, Tarrow and Tilly locate the critically important phase of the U.S. civil rights movement in the medium-sized city of Montgomery, Alabama. The causal reconstruction of this phase involves narratives about Rosa Parks's decision to violate the ordinance regulating race segregation on city buses. This in turn requires referencing Parks's history of civil rights activism and involvement in the local black church community. The explanation of the protest that followed her arrest and its escalation into a permanent mobilization makes reference to the existing network of organized civil right groups in Montgomery, as well as to political responses on the part of federal officials and southern segregationists. These responses were motivated by highly contextual decisions, such as the Kennedy Administration's consequent attempt at securing black votes for congressional stability.

But this does not mean that narrative explanations are one and the same thing as context-dependent explanation. Counterintuitive though it may sound, the narrative reconstruction of particular causes that form delimited mechanisms may lead to the identification of generalizable configurations of interaction between social actors and entities. So, for instance, the ability of activists to frame small-scale contentions as opportunities to mobilize crowds by appealing to a branded identity and escalate the intensity of the 
struggle is as characteristic of civil rights groups as it is of French Revolutionaries and Italian student activists in 1967-1968 (McAdam, Tarrow and Tilly 2001). Even in this third sense of "context-dependence", the actual degree of context-dependence or context-independence of MBE is an open question and needs not be determined a priori. Most importantly, it is not determined by a priori ontological considerations. Instead, it is influenced by the research strategy that is being adopted.

\section{Conclusion}

Discussions on mechanism-based explanation in the social sciences often revolve around different ways to understand the concepts of causal mechanism and MBE. As we showed above, some of these accounts presuppose that causal mechanisms are highly context-independent while others assume highly contextdependent mechanisms. If we think that these different notions of causal mechanisms and MBEs are mutually incompatible, we may easily end up debating essentially contested issues about the logic of explanation in the social sciences and the nature of causation.

However, once we pay attention to differences in methodological approaches and epistemic aims of social researchers, it is possible to make a distinction between three different ways in which MBEs can be said to be context-dependent. We termed them "theory-oriented context-dependence", "population-based context-dependence" and "case-oriented context-dependence". This distinction shows that different ideas about context-dependence of MBEs are connected to different goals or styles of social research rather than to mutually exclusive accounts of social mechanisms. Although these styles are often seen as competitors, they are better understood as complementing each other. One reason for this is that the epistemic limitations of each methodological approach are best seen by relating them to the complementary approaches.

At least two conclusions can be drawn from the above distinction. The first is that mechanism-based theorizing works in different ways in different methodological contexts. As a consequence, theoretical ideas about causal mechanisms that have been developed in a particular methodological context cannot be directly applied in the other types of methodological contexts. For example, ideas about intervening variables of population-level statistical models with intervening variables cannot be empirically tested by means of case- 
study research designs. Nor can abstract and highly idealized theoretical models be directly applied in case study designs that aim at producing relatively comprehensive mechanism-based explanations of outcomes in particular cases. The second conclusion is that these differences in aims and methodological presuppositions should not prevent interactions between social researchers who rely on different styles of doing explanatory social research. After all, they all also share the general objective of producing explanatory understanding of social phenomena.

Nevertheless, in current debates about mechanism-based explanations particular definitions of mechanisms that presuppose a particular methodological approach are often used to subordinate or to criticize all other methodological approaches. We suggest that, instead of engaging in this type of all-ornothing debate, a more fruitful way forward would be to develop a methodologically cooperative approach to mechanism-based theorizing and explanation. This would re-orient the debate from mutual misunderstanding between the parties to more interesting issues regarding how (or to what extent) explanatory knowledge produced in different methodological approaches can be integrated in a balanced way.

Finally, we do not deny that philosophical issues arise in attempts to integrate different methodological approaches in the social sciences. What we want to emphasize here is that there is no "miracle making" (Norkus 2005) account of mechanisms or causation that could be used to resolve these issues in a balanced way. Hence, we believe that philosophical issues about mechanisms are best addressed in a co-operative way that recognizes that social scientific research has many legitimate and complementary goals, and that no one methodological approach or account of mechanisms can serve them all.

\section{References}

Aronson, Jerrold L. 1984. A Realist Philosophy of Science. London and Basingstoke: Macmillan.

Azzi, Corry and Ehrenberg, Ronald. 1975. "Household Allocation of Time and Church Attendance." Journal of Political Economy 83 (1): 27-56. 
Beach, Derek and Rasmus B. Pedersen. 2013. Process-Tracing Methods: Foundations and Guidelines. Ann Arbor: The University of Michigan Press.

—. 2016. Causal Case Study Methods: Foundations and Guidelines for Comparing, Matching, and Tracing. Ann Arbor: The University of Michigan Press.

Bechtel, William. 2009. "Looking Down, Around, and Up: Mechanistic Explanation in Psychology." Philosophical Psychology 22 (5): 543-564.

Becker, Gary. 1976. The Economic Approach to Human Behavior. Chicago and London: The University of Chicago Press.

Bengtsson, Bo and Nils Hertting. 2014. "Generalization by Mechanism: Thin Rationality and Ideal-type Analysis in Case Study Research." Philosophy of the Social Sciences 44 (6): 707-732.

Bhaskar, Roy. 1978. A Realist Theory of Science. Brighton: The Harvester Press.

Biggs, Michael. 2009. "Self-Fulfilling Prophecies." In The Oxford Handbook of Analytical Sociology, edited by Peter Hedström and Peter Bearman, 294-314. Oxford: Oxford University Press.

Boero, Riccardo and Flaminio Squazzoni. 2005. “Does Empirical Embeddedness Matter? Methodological Issues on Agent-Based Models for Analytical Social Science." Journal of Artificial Societies and Social Simulation $8(4): 6$.

Braithwaite, Richard B. 1953. Scientific Explanation: A Study of the Function of Theory, Probability and Law in Science. Cambridge, UK: Cambridge University Press.

Bromberger, Sylvain. 1966. "Why Questions." In Mind and Cosmos: Essays in Contemporary Science and Philosophy, edited by Robert G. Colodny, 86-111. Pittsburgh: University of Pittsburgh Press.

Bunge, Mario. 1997. "Mechanism and Explanation.” Philosophy of the Social Sciences 27 (4): 410-465.

Collier, Ruth Berins, and David Collier. 1991. Shaping the Political Arena: Critical Junctures, the Labor Movement, and Regime Dynamics in Latin America. Princeton, NJ: Princeton University Press. 
Dean, Jeffrey S., George J. Gumerman, Joshua M. Epstein, Robert L. Axtell, Alan C. Swedlund, Miles T. Parker, and Stephen McCarroll. 2000. “Understanding Anasazi Culture Change Through Agent-Based Modeling." In Dynamics in Human and Primate Societies: Agent-Based Modeling of Social and Spatial Processes, edited by Timothy A. Kohler and George J. Gumerman, 179-205. Santa Fe Institute Studies in the Sciences of Complexity. New York and Oxford: Oxford University Press.

Elster, Jon. 1983. Explaining Technical Change. Cambridge, UK: Cambridge University Press.

—. 1989. Nuts and Bolts for the Social Sciences. Cambridge, UK: Cambridge University Press.

—. 1999. Alchemies of the Mind: Rationality and the Emotions. Cambridge, UK: Cambridge University Press.

—. 2007. Explaining Social Behavior. More Nuts and Bolts for the Social Sciences. Cambridge, UK: Cambridge University Press.

Falleti, Tulia G., and Julia F. Lynch. 2009. "Context and Causal Mechanisms in Political Analysis." Comparative Political Studies 42 (9): 1143-1166.

Friedman, Michael. 1974. "Explanation and Scientific Understanding." The Journal of Philosophy 71 (1): 5-19.

Garfinkel, Alan. 1981. Forms of Explanation: Rethinking the Questions in Social Theory. New Haven, CT: Yale University Press.

George, Alexander L., and Andrew Bennett. 2005. Case Studies and Theory Development in the Social Sciences. BCSIA Studies in International Security. Cambridge, MA and London: The MIT Press.

Gerring, John. 2010. “Causal Mechanisms: Yes, But...” Comparative Political Studies 23 (11): 1499-1526.

—. 2012. Social Science Methodology: A Unified Framework. Second Edition. Cambridge, UK: Cambridge University Press.

Gilbert, Nigel. 2008. Agent-Based Models. London: Sage.

Glennan, Stuart. 2010. “Ephemeral Mechanisms and Historical Explanation.” Erkenntnis (72) 2: $251-266$.

—, and Phyllis Illari (Eds). 2018. The Routledge Handbook of Mechanisms and Mechanical Philosophy. London: Routledge. 
Goldthorpe, John H. 2001. "Causation, statistics, and sociology." European Sociological Review, 120 (17): 120.

-. 2007. Critique and Program. Volume One of On Sociology. Stanford: Stanford University Press.

Gould, Roger V. (Ed.) 2004. The Rational Choice Controversy in Historical Sociology. Chicago: The University of Chicago Press.

Grüne-Yanoff, Till. 2009. “The Explanatory Potential of Artificial Societies.” Synthese 169 (3): 539-555.

—, and Paul Weirich. 2010. "The Philosophy and Epistemology of Simulation: A Review." Simulation \& Gaming 41 (1): 20-50.

Harré, Rom. 1970. The Principles of Scientific Thinking. London: Macmillan.

Hedström, Peter. 2005. Dissecting the Social: On the Principles of Analytical Sociology. Cambridge, UK: Cambridge University Press.

—, and Peter Bearman. 2009. "What Is Analytical Sociology All About? An Introductory Essay." In The Oxford Handbook of Analytical Sociology, edited by Peter Hedström and Peter Bearman, 4-24. Oxford: Oxford University Press.

—, and Richard Swedberg. 1998. "Social Mechanisms: An Introductory Essay." In Social Mechanisms: An Analytical Approach to Social Theory, edited by Peter Hedström and Richard Swedberg, 1-31. Cambridge, UK: Cambridge University Press.

—, and Lars Udehn. 2009. "Analytical Sociology and Theories of the Middle Range." In The Oxford Handbook of Analytical Sociology, edited by Peter Hedström and Peter Bearman, 25-47. Oxford: Oxford University Press.

—, and Petri Ylikoski. 2010. "Causal Mechanisms in the Social Sciences." Annual Review of Sociology 36: 4967.

Hempel, Carl G. 1965. “Aspects of Scientific Explanation." In Aspects of Scientific Explanation and Other Essays in the Philosophy of Science, 331-496. New York and London: The Free Press / Collier-Macmillan. 
Hernes, Gudmund. 1998. "Real Virtuality." In Social Mechanisms: An Analytical Approach to Social Theory, edited by Peter Hedström and Richard Swedberg, 74-101. Cambridge, UK: Cambridge University Press.

Illari, Phyllis McKay. 2011. "Mechanistic Evidence: Disambiguating the Russo-Williamson Thesis." International Studies in the Philosophy of Science 25 (2): 139-157.

Kaidesoja, Tuukka. 2019. "A Dynamic and Multifunctional Account of Middle-Range Theories." The British Journal of Sociology 70 (4): 1469-1489.

Kaldor, Nicholas. 1957. “A Model of Economic Growth.” The Economic Journal 67 (268): 591-624.

Khalifa, Kareem. 2004. “Erotetic Contextualism, Data-Generating Procedures, and Sociological Explanations of Social Mobility." Philosophy of the Social Sciences 34 (1): 38-54.

Kitcher, Philip. 1981. “Explanatory Unification.” Philosophy of Science 48 (4): 507-531.

Kiser, Edgar and Michael Hechter. 1991. "The Role of General Theory in Comparative-Historical Sociology." American Journal of Sociology 97 (1): 1-30.

_ 1998. "The Debate on Historical Sociology: Rational Choice Theory and Its Critics." American Journal of Sociology 104 (3): 785-816.

King, Gary, Robert O. Keohane, and Sidney Verba. 1994. Designing Social Inquiry: Scientific Inference in Qualitative Research. Princeton: Princeton University Press.

Knight, Carly R. and Christopher Winship. 2013. "The Causal Implications of Mechanistic Thinking: Identification Using Directed Acyclic Graphs (DAGs)". In Handbook of Causal Analysis for Social Research, edited by Stephen L. Morgan, 275-299. Dordrecht: Springer.

Little, Daniel. 2009. “The Heterogeneous Social: New Thinking About the Foundations of the Social Sciences.” In Philosophy of the Social Sciences: Philosophical Theory and Scientific Practice, edited by Chrysostomos Mantzavinos, 154-178. Cambridge, UK: Cambridge University Press. 
-. 2011. "Causal Mechanisms in the Social Realm". In Causality in the Sciences, edited by Phyllis McKay Illari, Federica Russo, and Jon Williamson, 273-295. Oxford: Oxford University Press.

—. 2016. New Directions in the Philosophy of Social Science. Lanham, MD: Rowman \& Littlefields.

Machamer, Peter, Lindley Darden, and Carl F. Craver. 2000. "Thinking About Mechanisms." Philosophy of Science 67 (1): 1-25.

Mahoney, James. 2001. "Beyond Correlational Analysis: Recent Innovations in Theory and Method." Sociological Forum 16 (3): 575-593.

Manicas, Peter T. 2006. A Realist Philosophy of Social Science: Explanation and Understanding. Cambridge, UK: Cambridge University Press.

Mayntz, R. 2004. "Mechanisms in the Analysis of Social Macro-Phenomena." Philosophy of the Social Sciences 34 (2): 237-59.

Mäki, Uskali. 2001. "Explanatory Unification: Double and Doubtful." Philosophy of the Social Sciences 31 (4): 488-506.

Maurer, Andrea. 2016. "Social Mechanisms as Special Cases of Explanatory Sociology: Notes toward Systemizing and Expanding Mechanism-based Explanation within Sociology." Analyse \& Kritik 38 (1): $31-52$.

McAdam, Doug, Sidney Tarrow, and Charles Tilly. 2001. Dynamics of Contention. Cambridge, UK: Cambridge University Press.

Merton, Robert K. (1948) 1968. Social Theory and Social Structure. Enlarged Edition. New York and London: The Free Press / Collier Macmillan.

Miller, John H. and Scott E. Page. 2007. Complex Adaptive Systems: An Introduction to Computational Models of Social Life. Princeton, NJ: Princeton University Press.

Morgan, Stephen L. and Christopher Winship. 2007. Counterfactuals and Causal Inference: Methods and Principles for Social Research. New York: Cambridge University Press. 
Morrison, Margaret. 2000. Unifying Scientific Theories: Physical Concepts and Mathematical Structures. Cambridge, UK: Cambridge University Press.

Norkus, Zenonas. 2005. "Mechanisms as Miracle Makers? The Rise and Inconsistencies of the 'Mechanismic Approach' in Social Science and History." History and Theory, 44(3): 348-372.

Opp, Karl-Dieter. 2005. "Explanations by mechanisms in the social sciences. Problems, advantages and alternatives." Mind \& Society 4 (2): 163-178.

Pawson, Ray. 2000. "Middle-range realism." European Journal of Sociology / Archives Européennes De Sociologie / Europäisches Archiv Für Soziologie 41 (2): 283-325.

Perrow, Charles. 2002. Organizing America: Wealth, Power and the Origins of Corporate Capitalism. Princeton and Oxford: Princeton University Press.

Pierson, Paul. 2000. "Increasing Returns, Path Dependence, and the Study of Politics." The American Political Science Review 94 (2): 251-267.

Quadagno, Jill and Stan J. Knapp. 1992. "Have Historical Sociologists Forsaken History? Thoughts on the History/Theory Relationship." Sociological Methods \& Research 20 (4): 481-507.

Risjord, Mark. 1999. “No Strings Attached: Functional and Intentional Action Explanations." In "Proceedings of the 1998 Biennial Meetings of the Philosophy of Science Association. Part I: Contributed Papers," S299-S313. Supplement, Philosophy of Science 66S.

-. 2000. Woodcutters and Witchcraft: Rationality and Interpretive Change in the Social Sciences. Albany: State University of New York Press.

Rodrik, Dani. 2015. Economics Rules. Oxford. Oxford University Press.

Rubinstein, Ariel. 2006. “Dilemmas of an Economic Theorist." Econometrica 74 (4): 865-83.

Ruonavaara, Hannu. 2012. "Deconstructing Explanation by Mechanism." Sociological Research Online 17(2):

7. 
Russo, Federica and Jon Williamson. 2007. "Interpreting causality in the health science." International Studies in the Philosophy of Science 21 (2): 157-170.

Salmon, Wesley C. 1984. Scientific Explanation and the Causal Structure of the World. Princeton: Princeton University Press.

Sayer, Andrew. 2010. Method in Social Science: A Realist Approach. Revised $2^{\text {nd }}$ Edition. Abingdon and New York: Routledge.

Schumpeter, Joseph A. (1954) 2006. History of Economic Analysis. Edited from manuscript by Elizabeth Boody Schumpeter and with an Introduction by Mark Perlman. Abingdon, UK and New York: Routledge.

Skocpol, Theda. 1994. Social Revolutions in the Modern World. Cambridge, UK: Cambridge University Press.

Smith, Vernon. 1975. "The Primitive Hunter Culture, Pleistocene Extinction, and the Rise of Agriculture." Journal of Political Economy 83 (4): 727-755.

Somers, Margaret R. 1998. "We're No Angels': Realism, Rational Choice, and Relationality in Social Science." American Journal of Sociology 104(3): 722-784.

Sørensen, Aage B. 1998. "Theoretical Mechanisms and the Empirical Study of Social Processes." In The Oxford Handbook of Analytical Sociology, edited by Peter Hedström and Peter Bearman, 238-266. Oxford: Oxford University Press.

Squazzoni, Flaminio. 2012. Agent-Based Computational Sociology. Chichester: Wiley.

Stinchcombe, Arthur L. 1992. "The Conditions of Fruitfulness of Theorizing About Mechanisms in Social Science." Philosophy of the Social Sciences 21 (3): 367-388.

Van Fraassen, Bas C. 1980. The Scientific Image. Oxford: Oxford University Press.

Weber, Max. (1904/1905) 2012. The Protestant Ethic and the Spirit of Capitalism. New York and Abingdon: Routledge.

Whewell, William. (1840-1847) 2014. The Philosophy of the Inductive Sciences Founded Upon Their History. Cambridge and New York: Cambridge University Press. 
Wimsatt, William C. 1976. "Reductive Explanation: A Functional Account." In PSA 1974: Proceedings of the 1974 Biennial Meeting of the Philosophy of Science Association, edited by Robert S. Cohen, C.A. Hooker, Alex C. Michalos, and James W. Van Evra, 671-710. Vol. XXXII of the Boston Studies in the Philosophy of Science, edited by Robert S. Cohen and Marx W. Wartofsky. Dordrecht: Reidel.

Woodward, J. (2003). Making Things Happen: A Theory of Causal Explanation. Oxford University Press, Oxford.

Ylikoski, Petri and Jaakko Kuorikoski. 2010. "Dissecting explanatory power." Philosophical Studies 148 (2): 201-219. 